\title{
Differences in Personality, Defense Styles, and Coping Strategies in Individuals with Depressive Disorder According to Age Groups Across the Lifespan
}

\author{
Miae Oh${ }^{1}$, Jong-Woo Kim¹, Nan-He Yoon², Seong Ae Lee ${ }^{3}$, Sang Min Lee ${ }^{1}$, and Won Sub Kang ${ }^{1}$ \\ ${ }^{1}$ Department of Psychiatry, College of Medicine, Kyung Hee University, Seoul, Republic of Korea \\ ${ }^{2}$ Department of Health Administration, Hanyang Cyber University, Seoul, Republic of Korea \\ ${ }^{3}$ Department of Psychiatry, Kyung Hee University Hospital, Seoul, Republic of Korea
}

Objective This study aimed to examine the differences in personality, defense style, and coping styles among patients with depression according to age groups.

Methods A total of 211 participants ranging from 19 to 81 years old were recruited for the study. To assess participants' five dimensions of personality, the Neuroticism-Extraversion-Openness Personality Inventory-Revised (NEO-PI-R) was administered. In addition, the Korean-Defense Style Questionnaire and the Korean version of the coping checklist were administered to examine the defense and coping style.

Results In the analysis of NEO-PI-R, the mean value of Agreeableness, Conscientiousness, and Neuroticism showed significant differences between the young adult age group (20-34 years) and the late middle age group (50-64 years) ( $\mathrm{p}<0.05)$. The young age group used more immature defense styles and made less use of problem-focused coping strategy than the old age patients (65 years and older) $(\mathrm{p}<0.05)$.

Conclusion In the young age group associations with lower Agreeableness and Conscientiousness, as well as higher Neuroticism than the late middle age group were observed. Moreover, the young age group had a higher usage of immature defense style, and restricted use of problem-focused coping style than other age groups.

Psychiatry Investig 2019;16(12):911-918

Key Words Depression, Personality, NEO-PI-R, Defense style, Coping strategy.

\section{INTRODUCTION}

The relationship between depressive disorder, personality traits, defense mechanism, and stress coping strategies has been of interest to researchers, but many studies have shown conflicting results. To evaluate the relationship between personality traits and depression, many studies used the Five-Factor Model (FFM) and have found that certain personality traits reflect vulnerability to depression. ${ }^{1-3}$ FFM conceptualizes personality in terms of five domains: Neuroticism, Extraversion, Open-

Received: June 28, 2019 Revised: August 28, 2019

Accepted: September 25, 2019

$\square$ Correspondence: Won Sub Kang, MD, PhD

Department of Psychiatry, College of Medicine, Kyung Hee University, 23 Kyungheedae-ro Dongdaemun-gu, Seoul 02447, Republic of Korea

Tel: $+82-2-958-8551$, Fax: $+82-2-957-1997$

E-mail: menuhinwskang@khu.ac.kr

(ac) This is an Open Access article distributed under the terms of the Creative Commons Attribution Non-Commercial License (https://creativecommons.org/licenses/bync/4.0) which permits unrestricted non-commercial use, distribution, and reproduction in any medium, provided the original work is properly cited. ness to Experience, Agreeableness and Conscientiousness. ${ }^{4,5}$ Several studies have shown that higher level of Neuroticism and lower level of Conscientiousness had strong associations with depression. ${ }^{3,-8}$ In addition, the relationship between stability of personality and age has been a subject of debate. Costa and Mc$\mathrm{Crae}^{9}$ have found that personality changes occur prior to the age of thirty and that personality remains stable afterward. Moreover, some scholars have argued that the FFM domains are relatively stable over time and are never influenced by a depressive episode. ${ }^{10,11}$ On the other hand, one study has shown that Extraversion and Neuroticism change before and after 30 years old. More specifically, according to longitudinal data from a national sample of Germans, Extraversion and Openness to Experience declined, whereas Agreeableness increased over the life span. ${ }^{12}$ Besides among young adults, Conscientiousness increased and then decreased in older adulthood. Lastly, Neuroticism slightly increased during middle age and decreased with age. ${ }^{13}$ 
Defense mechanisms are defined as automatic psychological processes that protect the individual against anxiety and from the awareness of internal or external dangers or stressors. Many studies have demonstrated that depressed patients are associated with immature defense styles. ${ }^{14-16} \mathrm{~A}$ recent crosssectional study found that hyperthymic or euthymic temperaments were associated with mature defense styles; whereas cyclothymic, depressive, dysphoric, or euphoric temperaments were more likely to present immature defense styles. ${ }^{17}$ Moreover, a systematic review has indicated that patients with depression present defense styles characterized by higher immature and neurotic defense styles and lower mature defense styles. ${ }^{14}$ There is a controversy in the understanding of the relationships between age and defense styles, one explanation being that the defense styles mature with age, ${ }^{18}$ and the other is that the defense styles worsen in an immature way with age..$^{19,20}$ Bronnec et al. ${ }^{21}$ reported that mature defense scores increased, whereas immature defense scores significantly decreased after a 28 day treatment for depression.

Coping efforts can be a goal-directed process that achieves these needs, in response to managing external or internal demands, protecting mechanism, or challenges to these needs. ${ }^{22}$ Many studies have found that more effective and realistic coping helps one control impulsivity and handle the situations more effectively. ${ }^{23,24}$ Lazarus and Folkman classified the coping strategies into problem-focused coping and emotion-focused coping. ${ }^{25}$ Problem-focused coping indicates attempts to eliminate the problem, and emotion-focused coping refers to, attempts to attenuate discomfort. A meta-analysis found that problem-focused coping is associated with good mental health, while emotion-focused coping is related to poor mental health. ${ }^{26}$ In addition, several studies have shown that emotion-focused coping is significantly relate to depression and anxiety. ${ }^{22,27,28}$ According to studies on the relationship between age and coping, younger people use more active, interpersonal, problemfocused forms of coping proportionately, the middle-age group use a more problem-focused solution and older people use more passive, intrapersonal, emotion-focused forms of coping. ${ }^{29,30}$ However, there is a dearth of studies to help explain the association between personality, defense styles, coping styles and age groups among patients with depression.

Therefore, the aim of this study was to examine the differences between personality traits, defense styles and coping strategies among patients with depression across four age groups.

\section{METHODS}

\section{Participants and procedure}

Between December 2014 and July 2016, participants were recruited from the inpatient and outpatient clinic of the psychiatric department at a university hospital in the Republic of Korea. Diagnosis of depressive disorder was confirmed for screened individuals by board-certified psychiatrists based on diagnostic criteria prescribed by the Diagnostic and Statistical Manual of Mental Disorder -IV-TR. ${ }^{31}$ Patients diagnosed with depressive disorder currently in acute phase or who were already diagnosed and being treated were participated. The Korean version of the Mini-International Neuropsychiatric Interviews (MINI) ${ }^{32}$ and the Korean version of Hamilton Depression Rating Scale (HAMD) ${ }^{33}$ were used to support diagnostic procedures. The study recruited 211 participants ranging from ages 19 to 81 , out of which 62 were men and the rest, women. Among 211 participants, 20 were excluded from the analysis, as some patients voluntarily opted out of the study and some left their scales incomplete. Analysis was therefore conducted using the data obtained from 191 individuals. The analysis was conducted in four groups which were divided on the basis of age. The young age group is classified by age under 35 and the old age group is over 65 and the middle-aged age was divided into two groups at intervals of 15 years. Therefore, the four age groups included, the young age group (20-34 years old), the middle age group ( $35-49$ years old), the late middle age group (50-64 years old), the old age group (65 years and older) and there were $42,36,70$, and 39 participants in each group, respectively. Exclusion criteria included: 1) history of major mental illness include schizophrenia, schizoaffective disorder, bipolar disorder, and major depressive disorder with psychotic features, 2) lack of parental understanding and cooperation because of Alzheimer's disease and intellectual disability, 3) history of alcohol and other substance abuse, and 4) clinically significant neurological or physical disease. Written informed consent was obtained from all participants, and the study was approved by the Institutional Review Board (IRB) of a university hospital (IRB no. 1443-05B).

\section{Measures}

\section{Hamilton Depression Rating Scale (HAM-D) ${ }^{34}$}

The Hamilton Depression Rating Scale (HAM-D) is a 17question scale, rated from 0 to 3 or 0 to 5 Likert-type in terms of intensity. The HAMD subscales include mood, anxiety, insomnia, suicidal ideation, guilty and somatic symptoms and are rated by a clinician. It also provides a rating of depression severity on a scale from 0 to 50 , with scores from 0 to 7 indicating remitted depression, 8 to 13 is mild depression, 14 to 18 is moderate depression, 19 to 22 is severe depression and 23 to 50 is very severe depression. The current study used the Korean version of the HAM-D which has developed by Yi et al. ${ }^{33}$ 
Five-factor model: NEO-personality inventory-revised $\left(\right.$ NEO-PI-R) ${ }^{35}$

NEO-personality inventory-revised (NEO-PI-R) is a selfreport inventory with 240-item assessment that measures the FFM domains of Neuroticism, Extraversion, Conscientiousness, Agreeableness and Openness to Experience. The questionnaire rated on a Likert scale ranging from 1 ("strongly disagree") to 5 ("strongly agree"). On the basis of T-scores (mean 50; $\mathrm{SD}=10)$ in an American normative sample, Costa and $\mathrm{McCrae}^{35}$ characterized the scale scores as average (45-55), high (56-65), very high (over 65), low (35-44), and very low (below 35). The psychometric properties of the Korean version of the NEO-PI-R are generally good. ${ }^{36}$

\section{Defense style: Korean-defense style questionnaire $(\mathrm{K}-\mathrm{DSQ})^{37}$}

The Korean-defense style questionnaire (K-DSQ) consists of 66 questions to evaluate defense types and each item is evaluated on a 7-point Likert-type scale, where 1 indicates 'completely disagree' and 7 indicates 'completely agree'. K-DSQ evaluates 16 defense mechanisms (acting out, projection, splitting, fantasy, humor, passive aggression, consumption, omnipotence, sublimation, denial, suppression, reaction formation, displacement, undoing, resignation, isolation) and classifies them into four defensive styles. The immature style consists of acting out, projection, splitting, fantasy, passive-aggression and consumption; the self-inhibiting style consisted of undoing, withdrawal, reaction formation and suppression; the adaptive style comprises the defenses humor, sublimation, denial, and omnipotence; the conflict-avoidance style consists of isolation and resignation.

\section{Coping style: the ways of coping checklist ${ }^{25,38}$}

The Korean version of the ways of coping checklist contains 62-items and the questionnaire comprised of a rating scale from 0 to 3, in which (0) indicates does not apply or not used, (1) indicates used somewhat, (2) indicates used quite a bit and (3) indicates used a great deal. The Korean version of the ways of coping checklist was divided into four groups: problem-focused coping (21 items), seeking social support (6 items), emotionfocused coping (23 items) and wishful thinking (12 items). In this study, the total sum was calculated and analyzed.

\section{Statistical analysis}

For continuous variables, differences according to age groups were analyzed using one-way analysis of variance (ANOVA); when significant main effects were present, this was followed by Scheffe's post hoc analysis. The outcomes were compared; adjusting for sex, education level, and HAM-D severity of the participants with regression analysis. All statistical analyses were conducted using SPSS Statistics 22 (IBM Corp., Armonk, NY, USA) and statistical significance was defined as $\mathrm{p}<0.05$.

\section{RESULTS}

Table 1 shows the summary of the baseline characteristics and the mean demographics. Out of 191 patients, 129 females

Table 1. Descriptive statistics for demographic variables

\begin{tabular}{|c|c|c|}
\hline Characteristic & Male & Female \\
\hline $\operatorname{Sex}(\%)$ & $62(32.5)$ & $129(67.5)$ \\
\hline \multicolumn{3}{|l|}{ Age group } \\
\hline $20-34$ & 25 & 17 \\
\hline $35-49$ & 10 & 32 \\
\hline $50-64$ & 20 & 46 \\
\hline $65+$ & 7 & 34 \\
\hline \multicolumn{3}{|l|}{ Education (\%) } \\
\hline 0 year & \multicolumn{2}{|c|}{$16(8.4)$} \\
\hline 6 years & \multicolumn{2}{|c|}{$20(10.5)$} \\
\hline 9 years & \multicolumn{2}{|c|}{$28(14.7)$} \\
\hline 12 years & \multicolumn{2}{|c|}{$76(39.8)$} \\
\hline Over & \multicolumn{2}{|c|}{$51(26.7)$} \\
\hline \multicolumn{3}{|l|}{ Occupation } \\
\hline Laborers & \multicolumn{2}{|c|}{13} \\
\hline Office workers & \multicolumn{2}{|c|}{9} \\
\hline Service workers & \multicolumn{2}{|c|}{25} \\
\hline Intermediate, advanced & \multicolumn{2}{|c|}{3} \\
\hline \multicolumn{3}{|l|}{ Managers } \\
\hline Professional & \multicolumn{2}{|c|}{2} \\
\hline Teachers & \multicolumn{2}{|c|}{4} \\
\hline Farmer, fisherman & \multicolumn{2}{|c|}{2} \\
\hline Soldiers & \multicolumn{2}{|c|}{1} \\
\hline Students & \multicolumn{2}{|c|}{15} \\
\hline Housewives & \multicolumn{2}{|c|}{79} \\
\hline Unemployed & \multicolumn{2}{|c|}{38} \\
\hline Familial psychiatric history (\%) & \multicolumn{2}{|c|}{$38(20)$} \\
\hline \multicolumn{3}{|c|}{ Number of depressive episode/s (\%) } \\
\hline 1 & \multicolumn{2}{|c|}{$80(41.9)$} \\
\hline 2 & \multicolumn{2}{|c|}{$38(19.9)$} \\
\hline 3 & \multicolumn{2}{|c|}{$23(12.0)$} \\
\hline 4 & \multicolumn{2}{|c|}{$16(8.4)$} \\
\hline Over 5 & \multicolumn{2}{|c|}{$34(17.8)$} \\
\hline Duration of illness (months) & 91.82 (minimu & , maximum: 612) \\
\hline $\begin{array}{l}\text { History of psychiatric } \\
\text { admission (\%) }\end{array}$ & & $9.9)$ \\
\hline HAM-D score (\%) & & \\
\hline Normal (0-7) & & 5.6) \\
\hline Mild (8-13) & & $9.3)$ \\
\hline Moderate (14-18) & & 3.8) \\
\hline Severe $(19-22)$ & & $9)$ \\
\hline Very severe (23-) & & 3) \\
\hline
\end{tabular}

HAM-D: Hamilton Depression Rating Scale 
Table 2. Differences in personality, defense styles, and coping strategies across age groups

\begin{tabular}{|c|c|c|c|c|}
\hline & $\begin{array}{c}\text { Age } \\
\text { (group) }\end{array}$ & Mean (SD) & $\mathrm{F}$ & $\begin{array}{c}\text { p-value } \\
\text { (post- } \\
\text { hoc test*) }\end{array}$ \\
\hline \multicolumn{5}{|l|}{ NEO-PI-R } \\
\hline \multirow[t]{4}{*}{ Extraversion } & $20-34(a)$ & $33.21(15.00)$ & 0.791 & 0.500 \\
\hline & $35-49$ (b) & 35.27 (8.78) & & \\
\hline & $50-64(\mathrm{c})$ & $36.55(10.81)$ & & \\
\hline & $65+(d)$ & $35.46(8.68)$ & & \\
\hline \multirow[t]{4}{*}{ Openness } & $20-34(a)$ & $40.31(13.72)$ & 0.238 & 0.870 \\
\hline & $35-49$ (b) & $38.32(10.97)$ & & \\
\hline & $50-64(c)$ & $38.56(12.46)$ & & \\
\hline & $65+(d)$ & $39.59(13.13)$ & & \\
\hline \multirow[t]{4}{*}{ Agreeableness } & $20-34(a)$ & $37.71(12.64)$ & 5.003 & $0.002^{* *}$ \\
\hline & $35-49$ (b) & $43.73(11.59)$ & & $(c>a, d>a)$ \\
\hline & $50-64(c)$ & 44.99 (13.87) & & \\
\hline & $65+(d)$ & $47.93(10.58)$ & & \\
\hline \multirow{4}{*}{$\begin{array}{l}\text { Conscien } \\
\text { tiousness }\end{array}$} & $20-34(a)$ & $46.29(13.29)$ & 0.440 & 0.724 \\
\hline & $35-49$ (b) & $48.81(10.03)$ & & \\
\hline & $50-64(c)$ & $49.08(14.77)$ & & \\
\hline & $65+(d)$ & $48.76(12.94)$ & & \\
\hline \multirow[t]{4}{*}{ Neuroticism } & 20-34 (a) & $64.69(12.65)$ & 4.553 & $0.004^{* *}$ \\
\hline & $35-49$ (b) & $58.76(11.15)$ & & $(a>c)$ \\
\hline & $50-64(c)$ & $55.49(15.47)$ & & \\
\hline & $65+(d)$ & $56.49(11.50)$ & & \\
\hline \multicolumn{5}{|l|}{ K-DSQ } \\
\hline \multirow[t]{4}{*}{ Immature } & $20-34(a)$ & $97.26(30.35)$ & 1.666 & 0.176 \\
\hline & $35-49$ (b) & $83.31(26.84)$ & & \\
\hline & $50-64(c)$ & $90.96(26.05)$ & & \\
\hline & $65+(d)$ & 90.77 (27.39) & & \\
\hline \multirow[t]{4}{*}{ Adaptive } & $20-34(a)$ & 40.93 (15.89) & 1.345 & 0.261 \\
\hline & $35-49$ (b) & $43.81(10.49)$ & & \\
\hline & $50-64(\mathrm{c})$ & $45.11(11.52)$ & & \\
\hline & $65+(d)$ & $46.03(12.32)$ & & \\
\hline \multirow{4}{*}{$\begin{array}{l}\text { Self- } \\
\text { inhibiting }\end{array}$} & $20-34(a)$ & $63.38(13.40)$ & 0.208 & 0.891 \\
\hline & $35-49$ (b) & $61.03(14.83)$ & & \\
\hline & $50-64(c)$ & $62.21(12.09)$ & & \\
\hline & $65+(d)$ & $62.31(12.96)$ & & \\
\hline \multirow{4}{*}{$\begin{array}{l}\text { Conflict- } \\
\text { avoiding }\end{array}$} & $20-34(a)$ & $21.00(7.31)$ & 0.645 & 0.587 \\
\hline & $35-49$ (b) & $18.72(6.83)$ & & \\
\hline & $50-64(c)$ & 20.14 (6.79) & & \\
\hline & $65+(d)$ & $20.31(8.66)$ & & \\
\hline \multicolumn{5}{|l|}{ Coping strategies } \\
\hline \multirow{4}{*}{$\begin{array}{l}\text { Problem- } \\
\text { focused }\end{array}$} & $20-34(a)$ & $23.52(11.14)$ & 3.957 & $0.009^{* *}$ \\
\hline & $35-49$ (b) & $28.08(13.91)$ & & $(c>a, d>a)$ \\
\hline & $50-64(c)$ & $31.10(13.56)$ & & \\
\hline & $65+(d)$ & $32.15(12.65)$ & & \\
\hline
\end{tabular}

Table 2. Differences in personality, defense styles, and coping strategies across age groups (continue)

\begin{tabular}{clccc}
\hline & \multicolumn{1}{c}{$\begin{array}{c}\text { Age } \\
\text { (group) }\end{array}$} & Mean (SD) & F $\begin{array}{c}\text { p-value } \\
\text { (post- } \\
\text { hoc test }^{*} \text { ) }\end{array}$ \\
\hline Seeking social & $20-34$ (a) & $6.48(4.75)$ & 1.851 & 0.140 \\
support & $35-49$ (b) & $7.94(4.39)$ & & \\
& $50-64(\mathrm{c})$ & $8.31(3.72)$ & & \\
& $65+(\mathrm{d})$ & $8.03(3.86)$ & & \\
Emotion- & $20-34(\mathrm{a})$ & $14.74(4.85)$ & 1.627 & 0.185 \\
focused & $35-49(\mathrm{~b})$ & $15.56(6.46)$ & & \\
& $50-64(\mathrm{c})$ & $17.11(6.26)$ & & \\
& $65+(\mathrm{d})$ & $16.64(5.79)$ & & \\
Wishful & $20-34(\mathrm{a})$ & $12.60(4.75)$ & 1.318 & 0.270 \\
thinking & $35-49$ (b) & $14.47(5.93)$ & & \\
& $50-64(\mathrm{c})$ & $14.73(5.96)$ & & \\
& $65+(\mathrm{d})$ & $14.15(5.87)$ & & \\
\hline
\end{tabular}

*by Scheffe's post-hoc test, ${ }^{* *} \mathrm{p}<0.05$. K-DSQ: Korean-Defense Style Questionnaire, NEO-PI-R: Neuroticism-Extraversion-Openness Personality Inventory-Revised

(67.5\%) included in the study had a mean duration of illness of 91.82 months (minimum: 1, maximum: 612). Among them, it was the first depressive episode for 80 patients (41.9\%) and $117(61.3 \%)$ patients had a stressful event before their episodes. With respect to the severity of depression, which was evaluated by HAM-D, 35.6\% of patients were in remission state and $29.3 \%$ were mild, $18.8 \%$ were moderate, $9.9 \%$ were severe, $6.3 \%$ were very severe.

Table 2 and Figure 1 demonstrate differences in personality, defense styles and coping strategies by age groups. As shown in Figure 1, In NEO-PI-R, Agreeableness increased with age, and the level of Agreeableness was significantly higher for those in the late middle age group (mean=44.99) and old age group (mean=47.93) compared to those in the young age group $($ mean=37.71) $(\mathrm{p}<0.05)$. On the contrary, Neuroticism tended to be significantly higher in the young age group, (mean=64.69) in comparison to the late middle age group $($ mean $=55.49)(\mathrm{p}<0.05)$. In analysis of $\mathrm{K}-\mathrm{DSQ}$, there was no statistically significant difference in defense styles with age groups. However, the young age group tended to use the immature, self-inhibiting and conflict-avoidance defense styles more than other age groups. On the other hand, adaptive defense style was used less among individuals in the young age group. In terms of coping strategies by age groups, the late middle age group (mean=31.10) and the old age group (mean=32.15) used a problem-focused coping strategy, significantly more than those in the young age group $($ mean $=23.52)(\mathrm{p}<0.05)$.

As shown in Table 3, after adjusting for confounding variables such as sex, educational level, and depression severity, 

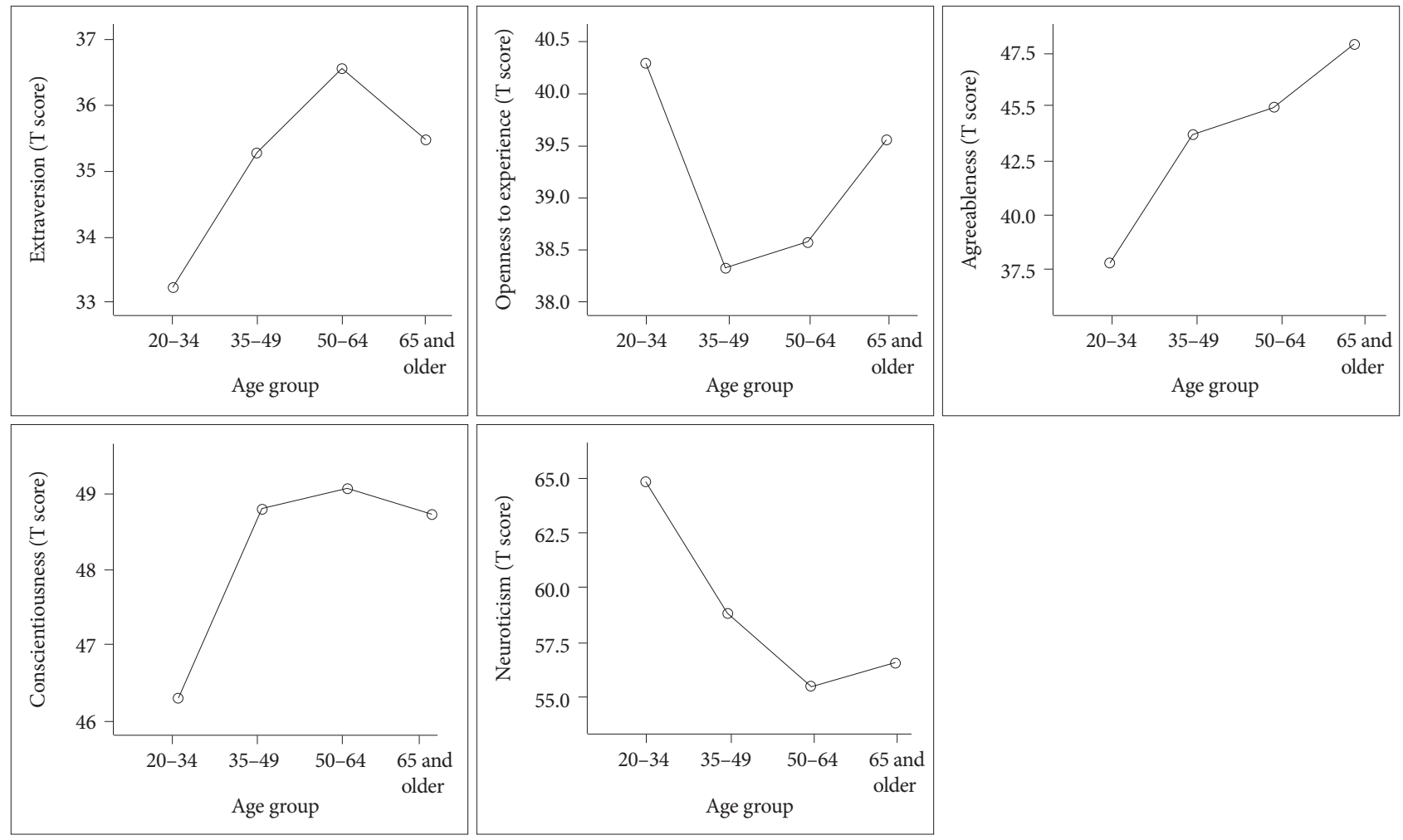

Figure 1. Differences in five personality factor according to age groups in the patients with depressive disorder.

Table 3. Regression analysis results after adjusting sex, educational level, and HAM-D severity

\begin{tabular}{|c|c|c|c|c|c|c|c|c|c|c|c|c|c|c|c|c|}
\hline \multirow{2}{*}{$\begin{array}{c}\text { NEO-PI-R } \\
\text { Age group }\end{array}$} & \multicolumn{3}{|c|}{ Extraversion } & \multicolumn{3}{|c|}{ Openness } & \multicolumn{3}{|c|}{ Agreeableness } & \multicolumn{4}{|c|}{ Conscientiousness } & \multicolumn{3}{|c|}{ Neuroticism } \\
\hline & $b^{*}$ & SE & $\overline{p \text {-value }}$ & $b^{*}$ & SE & $\mathrm{p}$-value & $\mathrm{b}^{*}$ & SE & $\overline{p \text {-value }}$ & $b^{*}$ & SE & $\mathrm{p}-\mathrm{v}$ & alue & $\mathrm{b}^{*}$ & SE & $\mathrm{p}$-value \\
\hline $20-34$ & \multicolumn{3}{|c|}{ (ref.) } & \multicolumn{3}{|c|}{ (ref.) } & \multicolumn{3}{|c|}{ (ref.) } & \multicolumn{4}{|c|}{ (ref.) } & \multicolumn{3}{|c|}{ (ref.) } \\
\hline $35-49$ & 2.413 & 2.941 & 0.414 & 2.413 & 2.941 & 0.414 & 5.609 & 3.513 & 0.113 & 4.048 & 3.435 & 0.24 & & -5.426 & 3.633 & 0.138 \\
\hline $50-64$ & 4.604 & 2.760 & 0.098 & 4.604 & 2.760 & 0.098 & 8.933 & 3.297 & $0.008^{* *}$ & 8.335 & 3.224 & 0.01 & $1^{* *}-$ & -13.211 & 13.410 & $0.000^{* *}$ \\
\hline $65+$ & -2.241 & 3.570 & 0.531 & -2.241 & 3.570 & 0.531 & 5.543 & 4.264 & 0.196 & 2.371 & 4.170 & 0.57 & & -7.577 & 4.410 & 0.088 \\
\hline \multicolumn{2}{|c|}{ K-DSQ } & \multicolumn{3}{|c|}{ Immature } & \multicolumn{4}{|c|}{ Adaptive } & \multicolumn{3}{|c|}{ Self-inhibiting } & & \multicolumn{4}{|c|}{ Conflict-avoiding } \\
\hline \multicolumn{2}{|c|}{ Age group } & $b^{*}$ & SE & $\mathrm{p}$-value & $b^{*}$ & SE & \multicolumn{2}{|c|}{$\mathrm{p}$-value } & $b^{*}$ & SE & \multicolumn{2}{|c|}{$\mathrm{p}$-value } & \multicolumn{2}{|c|}{$\mathrm{b}^{*}$} & \multirow{2}{*}{$\frac{\mathrm{SE}}{\text { (ref.) }}$} & \multirow[t]{2}{*}{$\mathrm{p}$-value } \\
\hline $20-34$ & & & (ref.) & & & (ref.) & & & & (ref.) & & & & & & \\
\hline $35-49$ & & -23.172 & 7.537 & $0.003^{* *}$ & 5.601 & 3.66 & 0.1 & 29 & -5.874 & 3.899 & 0.13 & & -2.68 & & 2.061 & 0.196 \\
\hline $50-64$ & & -17.256 & 7.074 & $0.016^{* *}$ & 3.913 & 3.435 & 0.2 & 257 & -6.579 & 3.659 & 0.07 & & -2.53 & & 1.935 & 0.192 \\
\hline $65+$ & & -15.487 & 9.149 & 0.093 & 2.978 & 4.443 & 0.5 & 504 & -7.438 & 4.733 & 0.11 & & 0.08 & & 2.502 & 0.973 \\
\hline Coping strat & egies & Probl & lem-focus & sed & Seek & king social & 1 suppor & & Em & ion fo & & & & Wishfu & ul thinki & \\
\hline Age grou & & $b^{*}$ & SE & $\mathrm{p}$-value & $\mathrm{b}^{*}$ & SE & $\mathrm{p}-\mathrm{v}$ & alue & $\mathrm{b}^{*}$ & SE & p-valu & & $b^{*}$ & & SE & $\mathrm{p}$-value \\
\hline $20-34$ & & & (ref.) & & & (ref.) & & & & (ref.) & & & & & (ref.) & \\
\hline $35-49$ & & 4.130 & 3.638 & 0.259 & 0.822 & 1.210 & 0.4 & 498 & 1.434 & 1.722 & 0.407 & & 1.538 & & 1.692 & 0.365 \\
\hline $50-64$ & & 9.813 & 3.414 & $0.005^{* *}$ & 2.446 & 1.136 & & $33^{* *}$ & 3.915 & 1.616 & 0.017 & $17^{* *}$ & 4.206 & & 1.588 & $0.009^{* *}$ \\
\hline $65+$ & & 9.549 & 4.416 & $0.033^{* *}$ & 1.866 & 1.469 & 0.2 & 207 & 4.257 & 2.090 & 0.04 & $44^{* *}$ & 3.65 & & 2.054 & 0.078 \\
\hline
\end{tabular}

${ }^{*}$ Coefficients adjusted for sex, educational level and HAM-D severity, ${ }^{* *} \mathrm{p}<0.05$. HAM-D: Hamilton Depression Rating Scale, K-DSQ; Korean-Defense Style Questionnaire, NEO-PI-R; Neuroticism-Extraversion-Openness Personality Inventory-Revised 
the results were similar except for significant results with respect to Conscientiousness in the NEO-PI-R. With regard to Agreeableness, Conscientiousness, and Neuroticism, there was a significant difference between the young age group and the late middle age group $(\mathrm{p}<0.05)$. There were no differences found in ANOVA (Table 2), but statistically significant differences were found between the young age group, middle and the late middle age groups in the regression analysis $(p<0.05)$, with respect to the immature defense style. A similar result was observed for the coping strategies in all the categories. Specifically, there was a significant difference between the young age group and the late middle age group. In addition, social support seeking and wishful thinking showed statistically significant differences in the old age group compared to the young age group $(\mathrm{p}<0.05)$.

\section{DISCUSSION}

Our study investigated differences in personality structure, defense style and coping strategies of patients with depression between four age groups. In terms of personality, the young age group showed lower Agreeableness and Conscientiousness and higher Neuroticism. The young age group used more immature defense styles and demonstrated less use of problemfocused coping strategy than the old age group patients.

There were various studies on the relationship between NEO-PI-R and depression, and several studies have reported an association between higher Neuroticism and lower Conscientiousness and depression in the young age group as compared to healthy controls. ${ }^{6,39-41}$ Our research also showed a link between high levels of Neuroticism and low levels of Conscientiousness and depression in the young age group. Higher Neuroticism is a risk factor for the onset of depression and has been suggested as a predictor of poor treatment response to depression. ${ }^{42}$ Weber et al. ${ }^{7}$ conducted a study with two groups: younger (25-50 years old) and elderly (6085 years old) group, and as a result, demonstrated a significant relationship between depression and Neuroticism. Both group showed higher Neuroticism, however among the old age group, the level of Neuroticism was lower than in the young age group. This could be explained by the fact that depression in old age may be associated with increased in physical burden including biologic changes and illnesses, on the contrary, stress and psychosocial factors are likely to induce depressive disorder at a young age. Lower Conscientiousness in the young age group was also observed in the current study, as compared to the late middle age group and the old age group. This has been a possible stable characteristic of depression and is associated more with an individual's poor health habits. ${ }^{43}$ Studies show that a possible explanation could be that lower Conscientiousness results in a lack of ability to address and manage life events or interpersonal relationships, which are in turn related to the onset of depression. ${ }^{1,6,44}$ Therefore, higher Neuroticism and lower Conscientiousness could lead to an increased vulnerability for depression in the young age group. It is clinically important to note the possibility of onset of depression in cases where there is high Neuroticism and low Conscientiousness in the young age group. ${ }^{8}$ On the other hand, lower Agreeableness is less consistent across the study. In this study, the young age group of depression showed lower Agreeableness than the middle age group and old age group. In previous studies, lower Agreeableness has been associated with negative treatment outcomes and great severity of depressive symptoms. ${ }^{45,46}$ In addition, a study has shown that lower Agreeableness was significant only as a risk factor for depression when accompanied by low Conscientiousness in elderly patients. ${ }^{47}$ Further research is needed on the causal relationship of having low Agreeableness in depressed young patients as a risk factor for depression.

Vaillant explained the defense styles by dividing it into three stages: immature, neurotic, and mature; mature defense styles are related to adaptive functioning and immature and neurotic defense styles are associated with individual's effort to maintain psychological homeostasis in a stressful circumstance. ${ }^{48}$ In our study, we divided the defense styles into immature, self-inhibiting, conflict avoidance and adaptive defense style. Research on the validity of the Korean version of DSQ explained that defense styles could also be divided into adaptive style and non-adaptive style (immature, self-inhibiting, conflict avoiding style). ${ }^{37}$ The results of our study demonstrated that the young age group was associated with the nonadaptive defense style and had a weak association with the adaptive defense style. Cramer's study revealed that the immature defense style was related to anxiety and depression in young adults and the mature defense style was related to the absence of depressive symptoms. ${ }^{49}$ In addition, according to a longitudinal study, elderly people tend to use less immature and neurotic defense styles and more mature defense styles. Therefore, with age, defense mechanisms became more and more organized into a stable structure.

In our study, the young age group of patients with depression were less likely to use problem-focused coping strategy than the late middle age group and old age group. This means that older people have a tendency to choose a way to solve problems directly rather than avoiding problems, which is consistent with previous studies. Previous studies showed that restricted use of problem focused coping was associated with the vulnerability of depression. ${ }^{50,51}$ In addition, several studies indicated that older adults use problem focused coping rather than avoidance coping strategies. ${ }^{20,47}$ Therefore, the results of these studies-includ- 
ing our study-suggest that a problem-focused coping could reduce depression in the young age group.

According to the results of our study, the young age group tends to be more anxious, depressed and frustrated than the old age group (high Neuroticism), lacking in tolerance or altruism (low Agreeableness) and lower level of self-regulation, sincerity and prudence (low Conscientiousness). This may lead to a tendency to cope with passive, negative, and impulsive rather than directly coping with stress, and this can increase vulnerability to depression. However, since our study employed a cross-sectional design, and did not take into account the type of stress. Future research is needed, as our study omits verification of causality among these factors. On the other hand, the old age group showed higher Agreeableness and less Neuroticism than the other two groups. According to previous studies, these characteristics are associated with lower risk of depression. Therefore, additional research is needed on factors affecting the onset of depression in elderly patients with depression. For this, comparative analysis with healthy controls is needed, along with due consideration for other social and environmental factors including physical conditions.

The current study has several limitations. Due to the crosssectional design, it is difficult to conclude the causality of the associations found between depression and personality, coping strategy and defense style. Second, because the HAM-D scores were widely distributed in each age group, so the severity of depression was likely to be a confounder. Third, the duration of depression was not adjusted. In other words, the differences in the personality, defense style, and coping strategies at the time of onset and the evaluation were overlooked. Finally, relative small sample size limits the generalizability of findings from the present study.

In the present study, we analyzed differences in personality, defense style, and coping strategy among patients with depressive disorder according to age groups. Many studies have been conducted to find out the link between depression and personality, defense style, and coping strategy. But so far, there have been no studies that identify the differences widely by dividing the age group across the lifespan. In young depressed patients, it was confirmed that having high Neuroticism and low Agreeableness and Conscientiousness, as well as immature defense style and less problem-focused coping, could serve as a vulnerability for the onset of depression. Thus, psychotherapeutic interventions targeting specific trait vulnerabilities are likely to be effective to the young age group in the depressive disorder. Also, the treatment considering personality, defense style, and coping strategy may have potential to decrease susceptibility to future episodes of depressive disorder. This is particularly meaningful in suggesting a clinical direction for setting therapeutic goals in psychotherapy to prevent the onset of depression in young patients. It will be also needed to conduct more study of the personality, defense style, and coping strategy changes occurring over the follow-up period in the depressive disorder patients. Further studies are required to confirm causal relationship between these factors.

\section{Conflicts of Interest}

The authors have no potential conflicts of interest to disclose.

\section{Author Contributions}

Conceptualization: Miae Oh, Jong Woo Kim, Won Sub Kang. Data curation: Miae Oh. Formal analysis: Miae Oh, Nan-He Yoon, Seong Ae Lee. Investigation: Miae Oh, Won Sub Kang. Methodology: Miae Oh, Jong Woo Kim, Won Sub Kang. Project administration: Jong Woo Kim, Won Sub Kang. Resources: Jong Woo Kim. Software: Miae Oh, Won Sub Kang. Supervision: Jong Woo Kim, Won Sub Kang. Validation: Jong Woo Kim, Won Sub Kang. Visualization: Miae Oh. Writing_original draft: Miae Oh, Sang Min Lee, Won Sub Kang. Writing_review \& editing: Miae Oh, Jong Woo Kim, Sang Min Lee, Won Sub Kang.

\section{ORCID iDs}

Won Sub Kang https://orcid.org/0000-0003-0495-2861

Miae Oh https://orcid.org/0000-0002-1927-3637

\section{REFERENCES}

1. Klein MH, Kupfer DJ, Shea MT. Personality and Depression: A Current View. New York: Guilford Press; 1993.

2. Enns MW. Personality dimensions and depression: review and commentary. Can J Psychiatry 1997;42:274-284.

3. Kendler KS, Myers J. The genetic and environmental relationship between major depression and the five-factor model of personality. Psychol Med 2010;40:801-806.

4. Costa PT Jr, McCrae RR. The Revised NEO Personality Inventory (NEO-PI-R). In The SAGE Handbook of Personality Theory and Assessment: Volume 2-Personality Measurement and Testing. London: SAGE Publications Inc., 2008, p.179-198.

5. Costa PT Jr, McCrae RR. Domains and facets hierarchical personality assessment using the Revised NEO Personality Inventory. J Pers Assess 1995;64:21-50.

6. Kotov R, Gamez W, Schmidt F, Watson D. Linking "big" personality traits to anxiety, depressive, and substance use disorders: a meta-analysis. Psychol Bull 2010;136:768-821.

7. Weber K, Giannakopoulos P, Bacchetta JP, Quast S, Hermann FR, Delaloye $\mathrm{C}$, et al. Personality traits are associated with acute major depression across the age spectrum. Aging Ment Health 2012;16:472-480.

8. Koorevaar AM, Comijs HC, Dhondt AD, van Marwijk HW, van der Mast RC, Naarding P, et al. Big five personality and depression diagnosis, severity and age of onset in older adults. J Affect Disord 2013;151:178-185.

9. Costa PT Jr, McCrae RR. Personality in adulthood: a six-year longitudinal study of self-reports and spouse ratings on the NEO Personality Inventory. J Pers Soc Psychol 1988;54:853-863.

10. Costa PT Jr, Bagby RM, Herbst JH, McCrae RR. Personality self-reports are concurrently reliable and valid during acute depressive episodes. J Affect Disord 2005;89:45-55.

11. Steunenberg B, Twisk JW, Beekman AT, Deeg DJ, Kerkhof AJ. Stability and change of neuroticism in aging. J Gerontol B Psychol Sci Soc Sci 2005;60:27-33.

12. Lucas RE, Donnellan MB. Personality development across the life span: longitudinal analyses with a national sample from Germany. J Pers Soc Psychol 2011;101:847-861.

13. Scollon CN, Diener E. Love, work, and changes in extraversion and 
neuroticism over time. J Pers Soc Psychol 2006;91:1152-1165.

14. Calati R, Oasi O, De Ronchi D, Serretti A. The use of the defence style questionnaire in major depressive and panic disorders: a comprehensive meta analysis. Psychol Psychother 2010;83:1-13.

15. Bond M, Perry JC. Long-term changes in defense styles with psychodynamic psychotherapy for depressive, anxiety, and personality disorders. Am J Psychiatry 2004;161:1665-1671.

16. Akkerman K, Lewin TJ, Carr VJ. Long-term changes in defense style among patients recovering from major depression. J Nerv Ment Dis 1999;187:80-87.

17. Carvalho AF, Hyphantis TN, Taunay TC, Macêdo DS, Floros GD, Ottoni GL, et al. The relationship between affective temperaments, defensive styles and depressive symptoms in a large sample. J Affect Dis 2013;146:58-65.

18. Vaillant GE. Natural history of male psychological health. V. The relation of choice of ego mechanisms of defense to adult adjustment. J Arch Gen Psychiatry 1976;33:535-545.

19. Shenfeld ME. The developmental course of defense mechanisms in later life. Int J Aging Hum Dev 1984;19:55-71.

20. Irion JC, Blanchard-Fields F. A cross-sectional comparison of adaptive coping in adulthood. J Gerontol 1987;42:502-504.

21. Bronnec M, Corruble E, Falissard B, Reynaud M, Guelfi JD, Hardy P. Reports on defense styles in depression. Psychopathology 2005;38:9-15.

22. Fear JM, Champion JE, Reeslund KL, Forehand R, Colletti C, Roberts L, et al. Parental depression and interparental conflict: children and adolescents' self-blame and coping responses. J Fam Psychol 2009;23:762-766.

23. Diehl M, Coyle N, Labouvie-Vief G. Age and sex differences in strategies of coping and defense across the life span. Psychol Aging 1996; 11:127-139.

24. Aldwin CM, Levenson MR. Stress, Coping, and Health at Mid-Life.: A Developmental Perspective. In: Lachman ME, Editor. The Handbook of Midlife Development. New York: John Wiley, 2001. p.188-214.

25. Lazarus RS, Folkman S. Stress, Appraisal, and Coping. New York: Springer Publishing Company; 1984.

26. Penley JA, Tomaka J, Wiebe JS. The association of coping to physical and psychological health outcomes: a meta-analytic review. J Behav Med 2002;25:551-603.

27. Nielsen MB, Knardahl S. Coping strategies: a prospective study of patterns, stability, and relationships with psychological distress. Scand J Psychol 2014;55:142-150.

28. Stevenson J, Brodaty H, Boyce P, Byth K. Does age moderate the effect of personality disorder on coping style in psychiatric inpatients? J Psychiatr Pract 2012;18:187-198.

29. Folkman S, Lazarus RS, Pimley S, Novacek J. Age differences in stress and coping processes. Psychol Aging 1987;2:171-184.

30. Richaud de Minzi MC, Sacchi C. Stressful situations and coping strategies in relation to age. Psychol Rep 2005;97:405-418.

31. American Psychiatric Association. Diagnostic and Statistical Manual of Mental Disorders: DSM-IV-TR. Washington, DC: American Psychiatric Press; 2000.

32. Yoo SW, Kim YS, Noh JS, Oh KS, Kim CH, NamKoong K, et al. Validity of Korean version of the mini-international neuropsychiatric interview. Anxiety Mood 2006;2:50-55.
33. Yi JS, Bae SO, Ahn YM, Park DB, Noh KS, Shin HK, et al. Validity and reliability of the Korean version of the Hamilton Depression Rating Scale (K-HDRS). J Korean Neuropsychiatr Assoc 2005;44:456-465.

34. Hamilton M. The Hamilton Rating Scale for Depression, in Assessment of Depression. Berlin: Springer, 1986, p.143-152.

35. Costa PT, MacCrae RR. Revised NEO Personality Inventory (NEO PIR) and NEO Five-Factor Inventory (NEO-FFI): Professional Manual. Odessa: Psychological Assessment Resources, Incorporated; 1992.

36. Lee KI, Ahn CG. Clinical application of the revised NEO personality inventory. Korean J Couns Psychother 1996;8:65-79.

37. Seong-Ho C. A validational study of Korean version of Defense Style Questionnaire. Korean J Couns Psychother 1999;11:115-137.

38. Kim JH, Lee CH. Relations of perceived stress, cognitive set, and coping behaviors to depression: a focus on freshmen's stress experiences. Korean J Couns Psychother 1988;6:26-45.

39. Clark LA, Watson D, Mineka S. Temperament, personality, and the mood and anxiety disorders. J Abnorm Psychol 1994;103:103-116.

40. Klein DN, Kotov R, Bufferd SJ. Personality and depression: explanatory models and review of the evidence. Annu Rev Clin Psychol 2011; 7:269-295.

41. Hayward RD, Taylor WD, Smoski MJ, Steffens DC, Payne ME. Association of five-factor model personality domains and facets with presence, onset, and treatment outcomes of major depression in older adults. Am J Geriatr Psychiatry 2013;21:88-96.

42. Mulder RT. Personality pathology and treatment outcome in major depression: a review. Am J Psychiatry 2002;159:359-371.

43. Anderson KW, Mclean PD. Conscientiousness in depression: tendencies, predictive utility, and longitudinal stability. Cogn Therapy Res 1997;21:223-238.

44. Oddone CG, Hybels CF, McQuoid DR, Steffens DC. Social support modifies the relationship between personality and depressive symptoms in older adults. Am J Geriatr Psychiatry 2011;19:123-131.

45. Canuto A, Meiler-Mititelu C, Herrmann F, Giannakopoulos P, Weber $\mathrm{K}$. Impact of personality on termination of short-term group psychotherapy in depressed elderly outpatients. Int J Geriatr Psychiatry 2008;23:22-26.

46. Löckenhoff CE, Sutin AR, Ferrucci L, Costa PT. Personality traits and subjective health in the later years: the association between NEO-PI-R and SF-36 in advanced age is influenced by health status. J Res Pers 2008;42:1334-1346

47. Felton BJ, Revenson TA. Age differences in coping with chronic illness. Psychol Aging 1987;2:164-170.

48. Vaillant GE. Involuntary coping mechanisms: a psychodynamic perspective. Dialogues Clin Neurosci 2011;13:366-370.

49. Cramer P. Defense mechanisms, behavior, and affect in young adulthood. J Pers 2002;70:103-126.

50. Lim YK CY, Choi JY. The relationship among temperament, character, coping style and depression in depressive patients. Korean J Clin Psychol 2013;32:331-350.

51. Littrell J, Beck E. Predictors of depression in a sample of African-American homeless men: identifying effective coping strategies given varying levels of daily stressors. Commun Ment Health J 2001;37:15-29. 